Article

\title{
Consultations with Children and Young People and Their Impact on Policy in Ireland
}

\author{
Deirdre Horgan \\ School of Applied Social Studies, University College Cork, Cork, Ireland; E-Mail: d.horgan@ucc.ie
}

Submitted: 29 March 2017 | Accepted: 25 July 2017 | Published: 26 September 2017

\begin{abstract}
This article will examine the participatory structures for consulting with children in Ireland. It provides a background with reference to the National Strategy on Children and Young People's Participation in Decision-making (Department of Children and Youth Affairs, 2015) - the first of its kind in Europe-its key objectives, and recent progress in meeting these. Examples of two consultations with children, on health and afterschool care, and their impact on policy, will be discussed. The potential for consultations of this kind to influence and child-proof policy will be reflected on; the argument in this article is that there are different levels of participation for different purposes. The author worked with colleagues on two national consultations in 2015 and 2016 involving children between 5 to 17 years of age utilising a variety of child-centred activities. The methods are strengths-based consultative approaches that allow children to identify and explore issues based on what they know and experience in their everyday lives. Initial reflections indicate that consultations with children can be an important and challenging tool in accessing their views on policy issues of importance to them which help to child-proof policy and ensure it is in the best interests of children.
\end{abstract}

\section{Keywords}

child participation; children's rights; consultations; Ireland; policymaking

Issue

This article is part of the issue "Promoting Children's Participation in Research, Policy and Practice", edited by Jo Aldridge (Loughborough University, UK).

(C) 2017 by the author; licensee Cogitatio (Lisbon, Portugal). This article is licensed under a Creative Commons Attribution 4.0 International License (CC BY).

\section{Introduction}

The Committee on the Rights of the Child suggested that the ways in which policy is developed and implemented is reflective of children's place in society and the political priority accorded to their rights (United Nations, 2003, para. 10). This article aims to show the potential of children's participation in national policymaking to mobilize policy change and to contextualize policy discussions.

The article briefly examines the child participatory agenda with a specific focus on consultation exercises. The policy context for children and young people's participation in Ireland is discussed including the participatory structures and mechanisms established in the past 25 years since Ireland's ratification of the United Nations Convention on the Rights of the Child (UNCRC). Child 'voice' in policy in Ireland is then reviewed through examination of two recent government consultation exercises with children and young people-consultations with 7 to 17 year olds on healthy lifestyles to inform the National Obesity Policy and Action Plan (Department of Health [DoH], 2016) and consultations with 5 to 12 year olds to inform the Action Plan on School Aged Childcare (Department of Children and Youth Affairs [DCYA] \& Department of Education and Skills [DES], 2017). The contention is that that there are different levels of participation for different purposes and that consultations, even as one-off exercises, can be an effective form of participation. The article concludes with some thoughts on auditing children's participation in consultation.

\section{Child Participation}

\subsection{Influences on the Child Participation Agenda}

The child participation agenda has been influenced by the UNCRC emphasis on children as rights holders, 
childhood studies perspectives on children as social actors, and more recent conceptualizations of the spatialrelational nature of children's lives (Horgan, Forde, Martin, \& Parkes, 2017). These influences have underpinned moves to promote children's inclusion as participants rather than 'apprentice adults' in society (Alanen, 2001). The UNCRC has put children on the social and political agenda. In particular, Article 12 commonly known as the 'Participation Article' is widely recognized as the basis for the child participation agenda in recent decades. It has been the catalyst for developing policy and practicebased participatory initiatives with children internationally (Percy-Smith, 2010).

\subsection{Consultation as Child Participation?}

Children's participation in decision-making is complex: it is undertaken for different purposes and is reflected in different levels of involvement, different contexts and different activities (Sinclair, 2004). A participation industry has developed since the UNCRC was published involving academics, researchers, participation officers, practitioners, and policymakers. Despite the flurry of participatory activity in recent years with innovative approaches and skilful facilitation, Shier, Hernandez Mendez, Centeno, Arroliga and Gonzalez $(2014$, p. 1) argue there is less evidence that children and young people's actions are having real influence on the policy-makers whose decisions affect their life-chances and well-being'. Similarly, Byrne and Lundy (2015) found little evidence of particular examples where children's views had informed a final policy. There is scant literature exploring face-to-face children's participation in public decision-making (PerryHazan, 2016) and a lack of empirical evidence of the discernible impact of children and young people's more general involvement in the policy process. Consequently, there is much need for analysis of how children's participation in the policy process can be meaningful, impactful and effective in bringing about change or, as Woodhouse (2003) puts it, how to include children as real partners in policy-making and implementation.

There is consensus that inclusion of children and young people's voice improves decision-making, creates better policy and services, and enhances democratic processes (Ahsan, 2009; Head, 2011; Lansdown, 2005; Wyness, 2012). Various patterns of children's participation are evident in public policymaking with Shier et al. (2014) outlining that, in the case of children and young people influencing public policy, 'influence' occurs in many ways, such as:

- Being a direct participant in a policy-making body;

- Acting in an advisory or consultancy role to policymakers;

- Meeting face-to-face with policy-makers, being listed to and taken seriously;

- Mobilising a large body of opinion to put pressure on policy-makers: marches, petitions, etc;
- Using the media effectively to give added force to your views.

The focus of this article is one-off consultation exercises with children and young people where their views are gathered to be used in decision-making and policy. Consultation exercises have often been seen by children and young people as sterile and unsatisfactory and experienced as an event rather than a process (Cairns, 2001). In Hart's (1997) ladder of participation, consultation would be placed on the middle rungs-'consulted and informed'-where youth are assigned specific roles and consulted about projects devised by others. Nonetheless, the argument in this article is that there are different levels of participation for different purposes. Shier (2001), in fact, points out that successful processes do not have to imply the highest step on the ladder and a fully developed participatory process might not always be the most suitable in a particular situation. Likewise, Head (2011, p. 546) maintains that full participatory roles and responsibilities are not feasible or necessary for every task or project. This article looks at two consultation exercises conducted with children and young people to inform key policy objectives related to health and afterschool care in Ireland. Both were designed as oneoff events but, despite the limitations of such a format, the argument is made that these can be effective tools in child-proofing policy and making it more meaningful. Some of the critical literature on child participation asserts that mainstream attempts to 'involve youth' in public affairs may sometimes be top-down, tokenistic and in some cases patronizing (Head, 2011; Perry-Hazan, 2016; Vromen, 2003). Critical reflection on these issues is necessary rather than assumptions that the fact of an initiative being undertaken in itself is a statement of success (Horelli, 1998). In the Irish context, these consultation exercises need to be more than a tick box exercise fulfilling government commitments to consult with children under the National Strategy on Children and Young People's Participation in Decision-making (DCYA, 2015).

\subsection{Challenges Related to Children's Meaningful Participation in Policy-Making}

Policymaking is one of the most challenging arenas in which children's participation rights are implemented (Perry-Hazan, 2016). Barriers to securing children's rights through policy include significant power gaps between children and policymakers (Nir \& Perry-Hazan, 2016). Government-led or official processes may function as a form of social control rather than empowering child participants (Cele \& van der Burgt, 2015; Nolas, 2015). In this regard, Nir and Perry-Hazan (2016) refer to 'framed participation' which grants children decision-making power, but constrains this power to within confined boundaries where adults determine the scope of participation. This requires us to question who controls the space, who sets the agenda, who decides who to invite, who con- 
trols the resources and above all, who decides what children and young people are allowed to do and what is prohibited (Shier et al., 2014). Further related to power issues, adultism or discrimination based on stereotype has been well documented in descriptions of participatory initiatives with children (Sinclair, 2004). For example, Perry-Hazan (2016) documents reactions of adult officials to children in committees in the Israeli parliament as fawning and infantilising. Exclusion of children who come from disempowered or minority families, younger children, those less academically and socially successful, and 'ordinary children' (Collins, Augsberger, \& Gecker, 2016; Nairn, Sligo, \& Freeman, 2006; Perry-Hazan, 2016) is another potential problem with participatory initiatives. Other barriers include institutional and procedural constraints (Adu-Gyamfi, 2013; Faulkner, 2009); and difficulty in guaranteeing the accountability of the participation process (Shier et al., 2014). Finally, Cele and van der Burgt (2015), discussing children's participation in physical planning in Sweden, point out that participants in their study comprising local planners, landscape architects, and researchers equated participation with consultation projects, but, few knew how to actually integrate the results of these methods into planning practice.

Co-operation between children and experienced adults can go beyond individual personal gains for the children involved (Kjørholt, 2002), with the potential to translate innovative ideas to effective practices and policy developments (Perry-Hazan, 2016). For this to happen, however, there must be consideration of what can make participation in policymaking meaningful and impactful for children and young people. Locating children's views alongside the views of the stakeholders is critical. Children's participation is often removed from the time and space where decisions are ultimately taken (Tisdall, 2015). When children's participation platforms are separated from those of adults, it is more likely to be tokenistic and to lack any impact, whereas joint projects have the potential of being more influential on policy (Gal, 2015). Marshall, Byrne and Lundy (2015, p. 378) in their study of children's direct contacts with policymakers in Northern Ireland concluded that this type of engagement enabled policymakers to understand children's lived experiences of their decisions more fully and resulted in these 'duty bearers' being more likely to follow up with meaningful actions in relation to the issues expressed by young people. Requirements for engagement of children in public decision-making include transparent and informative processes, in which children are informed regarding the scope of their potential influence and feel that their views have been acknowledged, valued, and taken seriously (Marshall et al., 2015). Research appears to indicate that most children and young people are more concerned that participation is meaningful and that decisions are explained to them rather than that their views are always acted upon (Davey, Shaw, \& Burke, 2010, in Horgan, Forde, Parkes, \& Martin, 2015). However, in public matters their participation may come from a desire to make a difference (Gal \& Faedi Duramy, 2015) and so can they often be disappointed with a lack of real change. Assessing the impact of children's participation, then, is an important step in including children in the policy conversation. Yet, the field of participatory policymaking is marked by a lack of evaluation, effective monitoring and follow-up on the impact of children's views on decisions (Shier et al., 2014).

\section{Policy Context for Children and Young People's Participation in Ireland}

In many countries, recent policy frameworks for addressing the well-being of young people have increasingly adopted a social inclusion approach and emphasise more avenues for the voices of young people (Head, 2011, p. 541). Article 12 of the UNCRC and its incumbent obligations has resulted in the Irish Government developing policies and practices that support the participation of children in decision-making across issues that affect their lives. The commitment to involving children and young people in decision-making became national public policy in 2000 with the publication of the National Children's Strategy which states: 'children will have a voice in matters which affect them and their views will be given due weight in accordance with their age and maturity' (Department of Health and Children, 2000, p. 11). Its successor, the National Framework for Children and Young People, commits to ensuring that 'Children are respected, connected and contributing' as one of its national outcomes and sets 'Listen to and involve children and young people' as a transformational goal (DCYA, 2014, p. 7).

\subsection{The Participatory Structures for Consulting with Children in Ireland}

Following the adoption of the UNCRC, various countries including Australia, Israel, Sweden, the Netherlands, and the UK established mechanisms facilitating children's participation at multiple governmental levels from local and regional to key government departments through child and youth councils, advisory boards, summits etc. (Perry-Hazan, 2016). In the Irish context, a Citizen Participation Unit, established within the DCYA in 2011, has been key to the development of participatory mechanisms and initiatives for children and young people. The role of the Unit is to ensure that children and young people have a voice in the design, delivery and monitoring of services and policies that affect their lives, at national and local level (DCYA, n.d.). Key structures for achieving this include Dáil na nÓg (national youth parliament), Comhairle na nóg (local youth councils), and a children and young people's participation support team. All of the work on Article 12 since Ireland's ratification of the UNCRC has culminated in the publication in 2015 of the National Strategy on Children and Young People's Participation in Decision-Making (DCYA, 2015), the first of its kind in Europe. 
The strategy is rooted in Article 12 of the UNCRC, and informed by Laura Lundy (2009)'s non-hierarchical, rights-based model of participation, emphasising space, voice, audience and influence elements to involving children in decision-making. The goal of the strategy is to ensure that children and young people have a voice in their individual and collective everyday lives and it prioritises key spaces and places where children are entitled to have a voice including their local communities, education, health and well-being, and the courts and legal system. A key objective of the strategy is central to the focus of this article, namely, 'mainstreaming the participation of children and young people in the development of policy, legislation and research' (DCYA, 2015, p. 4). Importantly, it highlights the role of policy-makers in realising this goal, committing Government departments and agencies and other stakeholders to involve children and young people in the development of policies, legislation and research.

\section{Child Voice in Policy-Consultations}

\subsection{Recent Consultations with Children and Young People and Their Impact on Policy}

The Irish government has conducted numerous consultations with children since the early 2000's on a range of policy issues. The DCYA claims that 'several of these consultations have resulted in significant developments in public policy and services, aimed at improving the lives of children and young people' (DCYA, n.d.). The author was part of a team recently commissioned by the DCYA to attend, record and write reports of two such consultations for government departments. The following discussion provides an overview of these consultations and briefly examines their initial impact on policy.

\subsection{Consultations with Children and Young People on Healthy Living}

One of the commitments of The National Strategy on Children and Young People's Participation in DecisionMaking (DCYA, 2015) was that the Department of Health would consult with young people as part of the development of a National Obesity Policy and any health promotion campaigns arising from that strategy. The consultations were conducted by the DCYA at two events, one with 48 children aged 8 to 12 and another with 34 young people aged 13 to 17 , in city centre locations in Dublin. Children were recruited through the Irish Primary Principals' Network (IPPN) with efforts made to include a range of primary school types including Catholic, non-denominational, Irish language, co-educational, single sex, urban and rural schools. Young people were recruited from the 31 Comhairle na nóg throughout the country. Considerable focus was placed on ensuring that good representation was achieved among participants regarding socio-economic status, gender, eth- nicity and geography. Methods used were innovative, age-appropriate and strengths based including warm-up exercises such as listening games, lifelines divided into key childhood stages in which children and young people reflected on their life experience to date regarding supports and obstacles to a healthy lifestyle, body mapping where the outline of one of the children's body was drawn onto a large sheet of paper and the children were asked to draw/write on the outline the things that make them healthy, floor mats divided into three sections: 'at home', 'at school' and 'in your area' where children were asked to think about what can make a child healthier in each of these contexts, world cafe workshops where key topic discussion zones were created to obtain more detail, and voting on the most important issues identified as barriers and facilitators of healthy living. These exercises were all done in small groups of six to eight with adult facilitators. The Healthy Lifestyles Have Your Say consultation report (DCYA/DoH, 2016) was published and launched alongside the National Obesity Policy and Action Plan (DoH, 2016).

The children ( 8 to 12 year olds) voted on the issues they felt were most important to a healthy lifestyle. They identified the following themes, in this order: choice of food, in particular more fruit and vegetables, drinking milk and water, getting enough vitamins and going to healthy restaurants; getting sufficient sleep; exercise and activity; not smoking; and supporting parents in enabling their children to be healthier. The following factors, listed in order of popularity, were identified by the young people (13 to 17 year olds) as facilitating a healthy lifestyle: magazines identifying images that have been photo shopped; good mental health and support; nutrition clinics; PE in schools that suits everyone's needs; school canteens selling healthy options; parents providing healthy food choices; listening to children; good teachers who guide students and relieve stress; and youth clubs.

The consultations impacted on the National Obesity Policy in a number of ways. The views of the participants assisted in framing the multi-dimensional approach incorporating the family, as well as the broader health environment of school, health services, local area planning and other determinants of health. Some specific actions in the policy which were informed by the views of children and young people include developing a 'whole of school' approach to healthy lifestyles programmes including the curriculum, on nutrition, physical activity and exercise, smoking, alcohol and mental wellbeing; developing and implementing training programmes for and by teachers on overweight and obesity, including antistigma; provision of potable water in schools; expanding parenting programmes that incorporate healthy lifestyle and behavioural change; development of guidelines and support materials for those working in urban development and planning in relation to reducing the obesogenic environment; and providing clinical services specifically for children. Overall, however, it is difficult to know what 
the process was in terms of utilising and prioritising children's views from the consultations given that some issues of importance to them, including PE in schools and issues related to mental health, are not fore fronted in the Action Plan.

\subsection{Afterschool Care Consultations}

Following commitments made in A Programme for Partnership Government (Department of the Taoiseach, 2016), and informed by consultations with a number of key stakeholders including children, the DCYA and the Department of Education and Skills published the Action Plan on School Age Childcare setting out actions to lead to a quality affordable system of 'out of school hours' childcare with a range of choices for parents and their children. Children were recruited by the DCYA from primary schools, as before, through the IPPN. Consultations with children were held as six one-off events lasting approximately three hours in a number of neutral settings around the country with 177 primary school children in total comprising 81 children aged 5 to 7 years and 96 children aged 8 to 12 years. The consultations with 5 to 7 year olds were conducted in their schools to enable smaller group work in a more familiar environment and were shorter in duration. The aims were to identify what children like and dislike about their current afterschool care arrangements and the places where children would most like to be cared for after school. Methods were strengths-based consultative approaches that allowed children to identify and explore issues based on what they know and experience in their everyday lives and on what they would like to change or improve on those issues. The consultations consisted of Ice-breaker games, a 'Post-it' activity to identify where children are currently cared for after school, a Placemat exercise where children were asked to draw/ write what they do and what they like to do after school on specially designed large floormats, a Timeline activity with children asked to design their ideal after-school experience on rectangular mats with a number of clouds depicting stages of the day after school, and Voting where children were given coloured cards to draw/write what they don't like about their day after school and put these into a ballot box. The consultations were subject to the standard ethical guidance and procedures for research with children (DCYA, 2017). All of the DCYA facilitators were very skilled and experienced in participatory work with children and young people and were police vetted.

The findings from the consultations with children commissioned for the Action Plan indicate that children want to be able to relax and feel comfortable after school. A home-like environment was preferred, with outdoor and indoor play identified as a priority of the afterschool experience by children of all ages. Relationships with family, extended family, friends, childminders and other carers were noted as being very important to children. Eating and cooking were also identified as important ac- tivities for children after-school. Children expressed a dislike of being in structured environments with rules. Other dislikes included not being treated appropriately for their age along with lack of food choice.

The consultation report (DCYA, 2017) was extensively referred to in the Action Plan and impacted on it in a number of ways. In terms of overall approach, the Action Plan states that the school age childcare model developed recognises the rights of children under the UNCRC and that the voice of children is critical to informing policy in this area. The Programme for Government, 2016, which prompted this policy contained proposals to support and expand quality after-school care based on utilising existing primary school buildings. While perhaps addressing issues related to locality and costs, this clearly would not address the limitations of such a direction as identified by children. The Action Plan (DCYA \& DES, 2017, p. 7), while still committed to the maximising the use of schools and existing community facilities which have suitable environments available for SAC 'where demand exists and where it can be facilitated by the school patron/ trustees', acknowledges that a homelike environment was preferred by many of the children consulted. 'If children's preference is to go home after school and enjoy certain patterns and activities, and it is not possible to facilitate this, then the system of SAC must seek to reproduce their preferences in a variety of settings, other than their home' (DCYA \& DES, 2017, p. 62), including exploring the potential role of the youth sector and ensuring quality standards in physical environment, adult/child ratios, the provision of appropriate food and nutrition, access to outdoor play, inclusion, and the health, well-being and protection of the child in all settings used. However, as with the previous consultation discussed, there are some aspects which did not find their way into the Action Plan. For example, while homework emerged strongly in the older children's timelines and reflects the reality of children's educational experiences and the practice of homework in the Irish education system, this is not dealt with in the Action Plan.

\section{Auditing Children's Consultations}

Drawing on the literature and the author's own experiences of participatory research and policy consultations with children and young people, the following are a number of issues which give some sense of how meaningful for children and how impactful on policy the consultation experience is. Together these could comprise some of the elements of an audit on children's participation in policy.

\subsection{Timeliness}

The timing of consultations with children can be critical. Children are often brought into the process too late and are only asked to comment or critique existing plans (Cele \& van der Burgt, 2015). Yet, Tisdall (2015) notes that 
while a last minute consultation may be pointless, too early may also be futile and theoretical in nature. A further problem that has been identified is the difference in time perspectives between children and adult stakeholders. Cele and van der Burgt (2015) argue that children need to see a result of their participation as soon as possible. As planners and policy-makers often have perspectives that reach over years, there must be some more immediate change to show children that they have been listened to. In this regard, the National Obesity Policy and Action Plan and the Action Plan on School Age Childcare were both published relatively quickly (within nine to ten months of the consultations with children being completed) which, on the surface at least, appears to indicate to those children involved that they had fed into and informed national policy issues.

\subsection{Participants}

The mix of participants in terms of background, age and whether or not they were regularly consulted children is an important consideration (Lansdown \& O'Kane, 2014). One of the consultations included Comhairle participants who could be considered 'youth leaders' (Checkoway, 2011), but both consultations invited participants who were involved as a one-off exercise and were from a variety of school types, geographic locations and socioeconomic backgrounds. With regard to the age of participants, Irish government departments have tended to consult with older children aged 8 years and upwards. This partly reflects a general societal view of younger children as less competent (Ahsan, 2009; Lansdown, 2005) and demonstrates that a child's participation is often valued in terms of how well she can adapt to adult practices (Cele \& van der Burgt, 2015). The afterschool care consultations, representing a new departure in practice, included children from 5 years of age with DCYA adult facilitators who had received specialised training from Early Childhood Ireland in age-appropriate creative engagement with younger children.

\subsection{Child-Friendly}

The consultation process was child friendly using a variety of age appropriate methods, including visual and verbal games, facilitated by trained staff, with plenty of breaks, and with refreshments provided for longer sessions with older children. While consultations generally took place in neutral venues, in some cases this was constrained by practical issues. For example, the decision to consult with younger children (aged 5 to 7 ) in smaller groups meant that these consultations had to take place within the children's school settings because of their earlier school finishing times. The potentially negative impact of the more structured and highly controlled space of the school on children's participation has been explored in research (Horgan, 2016; Spyrou, 2011). However, findings from these consultations indi- cate that the spatial context did not silence their opinions but also reflects the fact that most of the consultations were conducted outside of school settings to balance this potential. Children and young people are often dependent on whether or not child friendly versions of consultation documents are produced, and the ways in which these are made available by adult gatekeepers (Byrne \& Lundy, 2015). While, no children's version of the consultation reports were produced, the reports themselves were written in an accessible way with short summaries, key messages and lots of use of children's own words and drawings.

\subsection{Audience}

Ensuring that children's views are communicated to those with the responsibility to listen is critical. The Lundy checklist on audience in the National Strategy on Children and Young People's Participation in Decisionmaking (DCYA, 2015) asks, 'is there a process for communicating children's views? do children know who their views are being communicated to? and, does that person/body have the power to make the decisions?' Children were told at the outset of each consultation of the purpose of the exercise and the government department and Minister with responsibility to produce the policy informed by their views. In some cases officials from the relevant government departments attended part or all of the consultation. The process for communicating children's views was in the form of a report of the consultations written by academics, who attended the consultations and are familiar with participatory research/consultation work with children, for the DCYA and presented to the government departments responsible for the relevant policies on school age care and obesity.

\subsection{Information Gained}

In some cases what is considered to be 'good' information gained from children is information that 'can be used' by professionals and is 'planner-friendly' (Nairn et al., 2006). In these consultations, the team of facilitators were all trained in strengths-based participatory approaches with children, so that while discussions were fun and quite broadly based, they were also 'policy friendly' in the sense that they asked children about their experiences and opinions on healthy living including barriers and contributors or what they liked and disliked about their current afterschool care and their views on an ideal afterschool care experience.

\subsection{Dissemination}

'Deep participation' could be defined as that which involves young people in formulating the research questions right through to dissemination of the findings (Ansell, Robson, Hajdu \& van Blerk, 2012, in Horgan, 2016). Children's involvement in disseminating the find- 
ings of the consultations varied. Representative children and young people involved in the Healthy Lifestyles consultations were invited to the launch of the National Obesity Policy and asked to present a brief overview of their views and experiences. The DCYA prepared the children by briefing them on the consultation report findings and getting them to prioritise what they wanted to say. The launch of the school-age care policy did not involve the children. The process appears to be very much led by the Department which is developing the policy and has commissioned the consultation report. The DCYA sent copies of the consultation reports to all the schools that took part and asked them to let the children who participated see the reports.

\subsection{Impact}

Lansdown and O'Kane (2014) refer to wider external outcomes as those which indicate that a concrete change has happened in the community, or at local or national level, as a consequence of children's participation (including increased resources, regulation in an area). Returning to Lundy's checklist on Influence (DCYA, 2015): were children's views considered and taken seriously by those with the power to effect change? and, have the children been provided with feedback as to the reasons for decisions taken? There is evidence of children's views being incorporated into the final policy statements and Action Plans as discussed earlier, although the process as to which issues were prioritised is unclear. However, it appears that there is limited feedback to children involved in the consultations other than the policy reports themselves and media coverage surrounding the launches.

\subsection{Continuity}

Tisdall (2015) and Marshall et al. (2015) identify peaks with regard to children affecting public policy in contrast to ongoing sustainable inclusion of children in public policy formation. It is quite early in the process to evaluate this with regard to the Irish context given that the National Strategy on Children and Young People's Participation in Decision-making was published only two years ago, although activity since the publication has been strong. For practice to be meaningful, however, engagement with children must not end at the consultation, but requires ongoing dialogue.

\section{Conclusions}

Children's right to participate in public decision-making is increasingly being translated into practice in Ireland. Yet, we are only beginning to mine the potential of consultation as an aspect of child inclusion in public policymaking in Ireland. Reflection on the implications of such consultation practices for policies and services, drawing on recent results and analyses, is apposite. Generally, the consultations discussed appear to achieve in terms of timeliness, participant mix, child-friendly methods, connection to policymaker audience, and quality of information gained. However, real progress must be made in the areas of dissemination, impact and continuity. Policy development addressing the priorities of children, as discussed by them in consultations, could be viewed as child-proofed and child-informed policy. Given the arguments proposed in this article, that there are different levels of child participation for different purposes and that deep participation is not required for every purpose, consultations can be an important tool of the participation process. They contribute to policy grounded in children's realities and produce more responsive policy and services. However, to achieve this such consultations need to be organised and facilitated with knowledge, skill and respect for children's competencies as social actors, as well as with clear ideas on how to include the results from consultations in policy. There is considerable potential for child participatory policy development by embedding consultations of the kind discussed in this article as an integral part of policymaking, along with built in assessments of the long-term impact such views have on government delivery for children.

\section{Acknowledgements}

The author would like to thank the research teams including Shirley Martin, Jacqui O’Riordan, Margaret Scanlon and Jane O'Sullivan. Also, thanks to Anne O'Donnell of the Department of Children and Youth Affairs and Nazih Eldin of the Department of Health, and especially to the children who participated in the consultations.

\section{Conflict of Interests}

The author declares no conflict of interests.

\section{References}

Adu-Gyamfi, J. (2013). Can children and young people be empowered in participatory initiatives? Perspectives from young people's participation in policy formulation and implementation in Ghana. Children and Youth Services Review, 35(10), 1766-1772.

Ahsan, M. (2009). The potential and challenges of rightsbased research with children and young peoples' experiences from Bangladesh. Children's Geographies, 7(4), 391-403.

Alanen, L. (2001). Childhood as a generational condition: Children's daily life in a central Finland town. In L. Alanen \& B. Mayall (Eds.), Conceptualising child-adult relations (pp. 129-143). London: Falmer Press.

Ansell, N., Robson, E., Hajdu, F., \& van Blerk, L. (2012). Learning from young people about their lives: Using participatory methods to research the impacts of AIDS in southern Africa. Children's Geographies, 10(2), 169-186. 
Byrne, B., \& Lundy, L. (2015). Reconciling Children's policy and children's rights: Barriers to effective government. Children \& Society, 29(4), 266-276.

Cairns, L. (2001). Investing in children: Learning how to promote the rights of all children. Children \& Society, 15(5), 347-360.

Cele, S., \& van der Burgt, D. (2015). Participation, consultation, confusion: Professionals' understandings of children's participation in physical planning. Children's Geographies, 13(1), 14-29.

Checkoway, B. (2011). What is youth participation? Children and Youth Services Review, 33(2), 340-345.

Collins, M. E., Augsberger, A., \& Gecker, W. (2016). Youth councils in municipal government: Examination of activities, impact and barriers. Children and Youth Services Review, 65, 140-147.

Davey, C., Shaw, C., \& Burke, T. (2010). Children's participation in decision-making: A children's views report. London: Participation Works.

Department of Children and Youth Affairs. (n.d.). Consultations and participative initiatives with children and young people. Retrieved from https://www.dcya. gov.ie/viewdoc.asp?fn=\%2Fdocuments\%2FChildYouth Participation\%2FNational_Consultations.htm\&mn=c hiu5n\&nID=5

Department of Children and Youth Affairs. (2014). Better outcomes, brighter futures: The national policy framework for children and young people 2014-2020. Dublin: Government Publications Office.

Department of Children and Youth Affairs. (2015). National strategy on children and young people's participation in decision-making. Dublin: Government Publications Office.

Department of Children and Youth Affairs, \& Department of Health. (2016). Healthy lifestyles. Have your say: A consultation with children and young people. Dublin: Government Publications Office.

Department of Children and Youth Affairs, \& Department of Education and Skills. (2017). Action plan on school age childcare. Dublin: Government Publications Office.

Department of Children and Youth Affairs. (2017). Report of consultations with children on after-school care. Dublin: Government Publications Office.

Department of Health. (2016). A healthy weight for Ireland: Obesity policy and action plan 2016-2025. Dublin: Government Publications Office.

Department of Health and Children. (2000). Our children. Their lives: The national children's strategy. Dublin: Government Publications Office.

Department of the Taoiseach. (2016). A programme for partnership government. Dublin: Government Stationary Office.

Faulkner, K. M. (2009). Presentation and representation: Youth participation in ongoing public decisionmaking projects. Childhood, 16(1), 89-104.

Gal, T. (2015). From social exclusion to child-inclusive policies: Toward an ecological model of child par- ticipation. In T. Gal \& B. Faedi Duramy (Eds.), International perspectives and empirical findings on child participation: From social exclusion to childinclusive policies (pp. 451-463). Oxford: Oxford University Press.

Gal, T., \& Faedi Duramy, B. (Eds.). (2015). International perspectives and empirical findings on child participation: From social exclusion to child-inclusive policies. Oxford: Oxford University Press.

Hart, R. (1997). Children's participation. The theory and practice of involving young citizens in community development and environmental care. New York and London: UNICEF and Earthscan.

Head, B. W. (2011). Why not ask them? Mapping and promoting youth participation. Children and Youth Services Review, 33, 541-547.

Horelli, L. (1998). Creating child-friendly environments: Case studies on children's participation in three European countries. Childhood, 5(2), 225-239.

Horgan, D. (2016). Child participatory research methods: Attempts to go 'deeper'. Childhood. doi:10.1177/ 0907568216647787

Horgan, D., Forde, C., Martin, S., \& Parkes, A. (2017). Children's participation: Moving from the performative to the social. Children's Geographies, 15(3), 274-288.

Horgan, D., Forde, C., Parkes, A., \& Martin, S. (2015). Children and young people's experiences of participation in decision-making at home, in schools and in their communities. Dublin: Department of Children and Youth Affairs.

Kjørholt, A. T. (2002). Small is powerful: Discourses on 'children and participation' and Norway. Childhood, 9(1), 63-82.

Lansdown, G. (2005). The evolving capacities of the child (Innocenti Insights No.11). Florence: UNICEF Innocenti Research Centre.

Lansdown, G., \& O'Kane, C. (2014). A toolkit for monitoring and evaluating children's participation. UL: Save the Children.

Lundy, L. (2009). "Voice" is not enough: Conceptualising Article 12 of the United Nations Convention on the Rights of the Child. British Educational Research Journal, 33(6), 927-942.

Marshall, C., Byrne, B., \& Lundy, L. (2015). Face to face: Children and young people's right to participate in public decision-making. In T. Gal \& B. Faedi Duramy (Eds.), International perspectives and empirical findings on child participation (pp. 357-380). Oxford: Oxford University Press.

Nairn, K., Sligo, J., \& Freeman, C. (2006). Polarizing participation in local government: Which young people are included and excluded? Children, Youth and Environments, 16(2), 248-271.

Nir, T., \& Perry-Hazan, L. (2016) The framed right to participate in municipal youth councils and its educational impact. Children and Youth Services Review, 69, 174-183.

Nolas, S.-M. (2015). Children's participation, childhood 
publics and social change: A review. Children \& Society, 29, 157-167.

Percy-Smith, B. (2010). Councils, consultations and community: Rethinking the spaces for children and young people's participation. Children's Geographies, 8(2), 107-122.

Perry-Hazan, L. (2016). Children's participation in national policymaking: "You're so adorable, adorable, adorable! I'm speechless; so much fun!". Children and Youth Services Review, 67, 105-113.

Shier, H. (2001). Pathways to participation: Openings, opportunities and obligations. Children and Society, 15(2), 107-117.

Shier, H., Hernandez Mendez, M., Centeno, M., Arroliga, I., \& Gonzalez, M. (2014). How children and young people influence policy-makers: Lessons from Nicaragua. Children \& Society, 28, 1-14.

Sinclair, R. (2004). Participation in practice: Making it meaningful, effective and sustainable. Children \& Society, 18, 106-118.

Spyrou, S. (2011). The limits of children's voices: From authenticity to critical, reflexive representation. Child- hood, 18(2), 151-165.

Tisdall, E. K. M. (2015). Addressing the challenges of children and young people's participation: Considering time and space. In T. Gal \& B. Faedi Duramy (Eds.), International perspectives and empirical findings on child participation (pp. 381-404). New York: Oxford University Press.

United Nations. (2003). Committee on the Rights of the Child, General Comment No. 5 (General Measures of Implementation for the Convention on the Rights of the Child). Geneva: United Nations.

Vromen, A. (2003). "People try to put us down...": Participatory citizenship of "Generation X". Australian Journal of Political Science, 38(1), 79-99.

Woodhouse, B. B. (2003). Enhancing children's participation in policy formation youth, voice and power: Multi-disciplinary perspectives. Translating insights into policy. Arizona Law Review, 45, 751-764.

Wyness, M. (2012). Children's participation and intergenerational dialogue: Bringing adults back into the analysis. Childhood, 20(4), 429-442.

\section{About the Author}

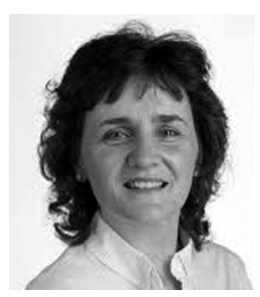

Deirdre Horgan (PhD) is a lecturer in Social Policy in the School of Applied Social Studies and Deputy Director of the BA (Early Years and Childhood) at UCC. Her research interests include child protection and welfare, children's rights and participation, children's research methods, and child migration. She has conducted a number of funded research projects using child participatory methods as well as reporting on government consultations with children on a range of policy issues. Deirdre has published on all of these topics in Child Abuse Review, Childhood, Children's Geographies, Race, Ethnicity and Education, and the European Journal of Social Work. 